\title{
UTILIZACIÓN DE LA PULPA DE CAFÉ ENSILADA COMO ALIMENTO PARA VACAS LECHERAS
}

Sandra Lorena Blandón Navarro

Maestra en Procesamiento de alimentos

Responsable de Investigación, UNI-Norte

sandra.blandon@norte.uni.edu.ni

\section{RESUMEN}

La pulpa de café es rica en nutrientes y su aprovechamiento puede ser potenciado a través del ensilaje. El estudio tuvo como finalidad evaluar el uso de la pulpa de café ensilada como alimento de vacas lecheras Bos taurus x Bos indicus, midiéndose su producción diaria. La primera fase de experimentación, realizada en época seca, constó de dos tratamientos, T1: Pasto disponible en la finca seleccionada, con concentrado comercial sin suplementar con el ensilaje y T2: Pasto disponible en la finca seleccionada más el concentrado comercial suplementado al $12 \%$ de ensilaje. En la segunda fase se modificó T2, aumentando al 30\% la suplementación con el ensilaje y se realizó en época de lluvias. Los resultados de ambas experimentaciones prueban que la pulpa de café ensilada con urea y melaza tiene un buen perfil de proteína cruda, superior al de la pulpa fresca y que en vacas en producción se puede sustituir parcialmente el concentrado comercial con pulpa de café ensilada sin afectarla negativamente. Por tanto, los productores de café, que poseen sistemas de producción diversificados, pueden aprovechar la pulpa en la alimentación de vacas en sistemas de doble propósito.

Palabras claves: Pulpa de café, ensilada, digestibilidad, degradación ruminal, ovinos.

\section{INTRODUCCIÓN}

Diferentes estudios llevados a la práctica sobre la utilización de la pulpa de café, como alimento animal, han demostrado que las principales limitantes para su utilización son sustancias antinutricionales que actúan como agentes inhibidores del crecimiento: Cafeína, Taninos y Polifenoles. Estas sustancias disminuyen la retención proteínica e inhiben la digestibilidad de las proteínas (Castellón, 2006).

Recientemente, estudios realizados en México, Venezuela, Brasil, Panamá y Ecuador han logrado demostrar, a través de la práctica del ensilaje aplicado a la pulpa, la eliminación parcial o total de estas sustancias antinutricionales y pueda ser utilizada como alimento animal en distintas especies, con diferentes porcentajes de inclusión.

Según Castellón, 2006, el éxito radica en la fermentación anaeróbica por bacterias lácticas que producen ácido láctico disminuyendo el $\mathrm{pH}$ a 4.2, el cual inhibe el crecimiento de agentes patógenos y así se conserva las características nutricionales del producto ensilado.

\section{MATERIALES Y MÉTODOS}

La investigación se llevó a cabo en la Finca "El Aguacate", ubicada en la comunidad "Los Jobos", a un kilómetro al sur de la ciudad de Estelí y tuvo como finalidad evaluar el efecto de la pulpa de café ensilada sobre la producción de leche en vacas cruzadas Bos taurus x Bos indicus. En la primera etapa, se utilizaron 6 vacas de aproximadamente $430 \mathrm{~kg}$ de peso vivo en el primer periodo de lactancia. Estas fueron manejadas en pastoreo, en época de verano.

Los tratamientos experimentales fueron los siguientes: Tratamiento 1, pastoreo más concentrado comercial y Tratamiento 2 , pastoreo, concentrado comercial más pulpa de café ensilada, 
suministrada al $12 \%$. La variable medida fue la producción de leche, para la cual las vacas fueron ordeñadas una sola vez por la mañana, la leche fue pesada diariamente durante el período de medición o toma de datos. Se ordeñaron completamente tres de los cuartos, dejando un cuarto para la alimentación del ternero.

En la segunda etapa se utilizaron vacas en el tercer periodo de lactancia, en época de invierno. Los tratamientos experimentales en esta etapa fueron: Tratamiento 1, pastoreo más concentrado comercial y Tratamiento 2, pastoreo, concentrado comercial más pulpa de café ensilada, suministrada al $30 \%$. La variable medida fue la misma que en la primera etapa.

\section{RESULTADOS Y DISCUSIÓN}

En la figura 1 se presentan los resultados de la producción de leche por vaca y día, los mismos demuestran que no hubo diferencias entre los tratamientos $(\mathrm{P}>0.05)$. La diferencia entre los tratamientos es solamente 0.57 litros por vaca y día entre el tratamiento 1 suplementado con concentrado y el tratamiento 2. Se le suministró concentrado más 4 libras ensilaje de pulpa de café. No se presentó efectos negativo de la pulpa de café sobre la producción de leche.

Al respecto, Ribeiro et al., (2000), reporta que hay una tendencia lineal a disminuir el comportamiento productivo a medida que incrementa la cantidad de pulpa de café incluida en la dieta. En el presente estudio no se presentó un efecto negativo por que el nivel de inclusión de la pulpa de café ensilada sólo representó el $12 \%$ del suplemento en base seca.

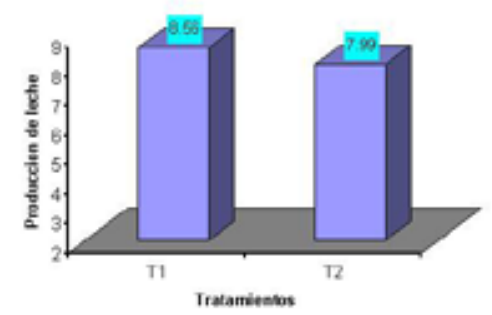

Figura 1. Producción de leche en vacas cruzadas (Bos taurus $x$ Bos indicus).

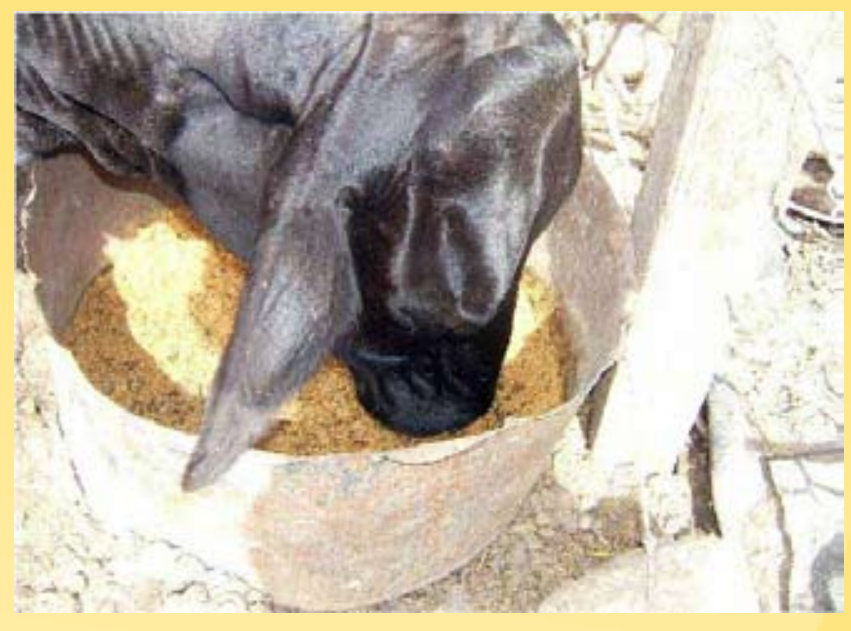

Figura 2. Vaca consumiendo mezcla de pulpa de café ensilada (al 12\%) con concentrado comercial

En la segunda etapa, los resultados de la producción de leche por vaca por día, demuestran que no hubo diferencias entre los tratamientos $(\mathrm{P}>0.05)$, aunque la producción tuvo una tendencia a disminuir al utilizar la pulpa de café. La diferencia fue 0.8 litros/vaca/día mayor el tratamiento 1 que en el tratamiento 2, donde se sustituyó el $30 \%$ del concentrado por la pulpa de café ensilada.

El nivel de producción obtenido entre 7.1 y 7.9 litros por vaca por día, mostrado en la figura 3, probablemente hubiese sido mayor si las vacas hubiesen estado en la primera etapa de lactancia que es donde mayor respuesta se tiene con la suplementación.

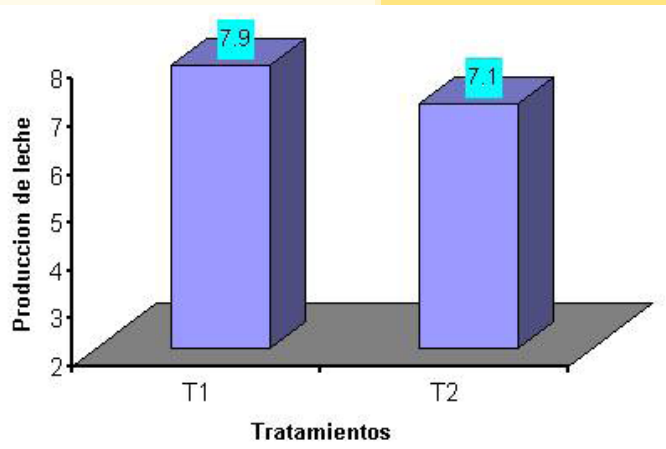

Figura 3. Producción de leche en vacas cruzadas (Bos taurus $x$ Bos indicus) en pastoreo suplementadas con pulpa de café ensilada más concentrado o concentrado en la época de lluvias 
Es importante recalcar que la producción obtenida al suplementar con pulpa de café ensilada es buena y no difiere de la no suplementada, aún cuando las vacas en esta época tienen buena disponibilidad de pasto y seleccionan una dieta de mejor calidad.

La pulpa de café ensilada no sólo es buena para la alimentación del ganado en el verano sino también en el invierno y que al suplementar con pulpa de café ensilada a nivel del $30 \%$ en base seca a vacas en pastoreo en la época de lluvias, puede contribuir a incrementar la carga animal y con ello incrementar la producción por área.

\section{Costos de producción de la pulpa de café ensi- lada}

Para el cálculo de los costos de producción, se determinó: costo de materia prima y mano de obra.

El costo de la pulpa de café se consideró igual a 0 , lo recomendable es que los productores de café sean los mismos que procesen. A volúmenes más grandes de producción los costos se reducen.

El costo de producción calculado para 1 barril de pulpa ensilada, equivale a $146.4 \mathrm{~kg}$ de alimento. Para la misma cantidad del concentrado comercial $(146.4 \mathrm{~kg})$, será necesario invertir C\$ 1127.28 en comprarlo.

Por otro lado, es relevante abordar que el productor debe hacer una inversión inicial igual a C\$ 1000.00 , la cual se detalla en el cuadro presentado a continuación.

\begin{tabular}{|l|l|l|l|}
\hline Requerimiento & Cantidad & $\begin{array}{c}\text { Costo } \\
\text { Unitario } \\
\text { CS }\end{array}$ & $\begin{array}{c}\text { Costo } \\
\text { total CS }\end{array}$ \\
\hline Barril plástico & 1.00 & 500.00 & 500.00 \\
\hline $\begin{array}{l}\text { Pesa quintalera } \\
\text { Panas plásticas, }\end{array}$ & 1.00 & 380.00 & 380.00 \\
\hline $\begin{array}{l}\text { capacidad de } 20 \\
\text { litros }\end{array}$ & 2.00 & 60.00 & 120.00 \\
\hline $\begin{array}{l}\text { Inversión total CS } \\
\text { Inversión total en \$ }\end{array}$ & & 1000.00 \\
\hline
\end{tabular}

Todos estos requerimientos pueden ser reutilizados en el proceso de elaborar el alimento animal. La inversión puede aumentar en función de la cantidad de pulpa que se vaya a ensilar.

\section{CONCLUSIONES}

El alimento formulado se puede utilizar en la alimentación de vacas en producción, sustituyendo un $12 \%$ del concentrado comercial en base seca y esto no afectará negativamente la producción.

Asimismo, la pulpa de café ensilada puede sustituir hasta un $30 \%$ del concentrado comercial sin afectar la producción de leche de las vacas en pastoreo en invierno.

La pulpa de café es un subproducto agrícola que puede ser utilizado en la alimentación de vacas en ganaderías de doble propósito, contribuyendo al sostenimiento de los animales, tanto en época de verano como en época de invierno.

La elaboración del alimento, utilizando como materia prima la pulpa de café es rentable y los costos de producción resultan muy bajos en relación a adquirir el concentrado comercial.

\section{BIBLIOGRAFÍA}

- Castellón M. 2006. Utilización de la pulpa de café para la alimentación animal a través de un proceso de fermentación en estado sólido, FESPCAFE. Presentación en Power Point. $46 \mathrm{pp}$

- Ribeiro, E. De Aguiar, P.C. Ferreira, A. Pereira, C.A, Maciel, R. Lucía, V. 2000. Efeito da casca de café (Coffea arabica, L.) no desempenho de novilhos mestiços de holandês-zebu na fase de recria. Ciénc. agrotec., Lavras, v.24, n.1, p.225-232, jan./mar., 2000 